\title{
A novel physiological culture system that mimics luteal angiogenesis
}

\author{
R S Robinson ${ }^{1}$, A J Hammond ${ }^{2}$, G E Mann ${ }^{2}$ and M G Hunter ${ }^{2}$ \\ ${ }^{1}$ School of Veterinary Medicine and Science and ${ }^{2}$ School of Biosciences, University of Nottingham, Sutton Bonington \\ Campus, Loughborough, Leics LE12 5RD, UK
}

Correspondence should be addressed to R S Robinson; Email: bob.robinson@nottingham.ac.uk

\begin{abstract}
Luteal inadequacy is a major cause of poor embryo development and infertility. Angiogenesis, the formation of new blood vessels, is an essential process underpinning corpus luteum $(\mathrm{CL})$ development and progesterone production. Thus, understanding the factors that regulate angiogenesis during this critical time is essential for the development of novel strategies to alleviate luteal inadequacy and infertility. This study demonstrates the development of a physiologically relevant primary culture system that mimics luteal angiogenesis. This system incorporates all luteal cell types (e.g. endothelial, steroidogenic cells, fibroblasts and pericytes). Using this approach, endothelial cells, identified by the specific marker von Willebrand factor (VWF), start to form clusters on day 2, which then proliferate and develop thread-like structures. After 9 days in culture, these tubule-like structures lengthen, thicken and form highly organized intricate networks resembling a capillary bed. Development of the vasculature was promoted by coating wells with fibronectin, as determined by image analysis $(\boldsymbol{P}<\mathbf{0 . 0 0 1})$. Progesterone production increased with time and was stimulated by $\mathrm{LH}$ re-enforcing the physiological relevance of the model in mimicking in vivo luteal function. LH also increased the area stained positively for VWF by twofold $(P<0.05)$. Development of this endothelial cell network was stimulated by fibroblast growth factor 2 and vascular endothelial growth factor $A$, which increased total area of VWF positive staining on day 9 , both independently (three- to fourfold; $P<0.01$ ) and in combination (tenfold; $P<\mathbf{0 . 0 0 1}$ ). In conclusion, the successful development of endothelial cell networks in vitro provides a new opportunity to elucidate the physiological control of the angiogenic process in the developing CL.

Reproduction (2008) 135 405-413
\end{abstract}

\section{Introduction}

Angiogenesis, the formation of new blood vessels, is a critical component of normal follicular and luteal function (Plendl et al. 1996). Follicular vasculature develops during follicular growth and by the preovulatory stage, capillary networks have formed in the theca layers, although the granulosa cell layer remains avascular (Redmer \& Reynolds 1996, Fraser \& Wulff 2001). Follicle-luteal transition is a dynamic process, which involves a series of biochemical and morphological changes in the pre-ovulatory follicle induced by the luteinizing hormone (LH) surge (Reynolds \& Redmer 1999, Niswender et al. 2000). These include the differentiation of theca and granulosa cells into luteal cells, extensive tissue remodelling and growth and a steroidogenesis switch to increasing progesterone production. In order to meet these demands, the growth of blood vessels and establishment of a blood supply (angiogenesis) are essential (Reynolds \& Redmer 1999, Fraser \& Lunn 2001, Schams \& Berisha 2004). Angiogenesis is so intense that $85 \%$ of the proliferating cells are of vascular origin. This enables the corpus luteum $(\mathrm{CL})$ to grow at a rapid rate ( $0.5 \mathrm{~g}$ to $>5 \mathrm{~g}$ in 5 days) that is only surpassed by the fastest growing tumours. This process is essential for sufficient progesterone to be produced to support the developing embryo. By the mid-luteal phase, every steroidogenic luteal cell lies adjacent to an endothelial cell and the CL has the highest size-adjusted blood flow of any organ (Reynolds et al. 2000).

The critical importance of angiogenesis in luteal development was shown by the immunoneutralization of vascular endothelial growth factor A (VEGFA) at ovulation in marmosets, which blocked the development of normal capillary bed. Moreover, there was a marked suppression in post-ovulatory progesterone concentrations (Fraser et al. 2000, Zimmermann et al. 2001). Preliminary experiments in the cow also found that VEGFA antibody administration adversely affected luteal growth, and the post-ovulatory rise in progesterone was delayed (Kamada et al. 2004). This emphasizes the link between angiogenesis and progesterone concentrations and subsequently embryo development. This is particularly important in the cow, where as little as a day's delay in the rise of post-ovulatory concentrations has been associated with retarded embryo development, reduced 
interferon- $\tau$ production and a failure to establish pregnancy (Larson et al. 1997, Mann \& Lamming 2001). This also represents a major reproductive problem for a number of other species.

While there is a plethora of angiogenic growth factors, the principal ones are considered to be VEGFA and fibroblast growth factor 2 (FGF2) with other factors playing lesser roles. VEGFA and FGF2 are potent stimulators of both endothelial cell proliferation and migration (Carmeliet 2003, Ferrara et al. 2003). Both VEGFA and FGF2 mediate their action through their high affinity tyrosine kinase receptors, namely VEGF receptor (VEGFR)-1 and VEGFR-2 and FGF receptor (FGFR)- 1 and FGFR-2 respectively (Ferrara et al. 2003, Wiedlocha \& Sorenson 2004). In the pre-ovulatory follicle, granulosa cells are the major source of VEGFA, while FGF2 is mainly theca derived (Berisha et al. 2000a, Greenaway et al. 2005). Contrary to expectation, we have recently showed that FGF2 production, rather than VEGFA, is the dynamic driver during the follicle-luteal transition and early CL development in the cow (Robinson et al. 2007). Specifically, follicular fluid concentrations of FGF2 increased dramatically post-LH surge and were maintained at high concentrations in the collapsed follicle but declined thereafter. Conversely, there was no such up-regulation of VEGFA during the follicle-luteal transition. This suggested that FGF2 may be the initiator of luteal angiogenesis in the cow.

While it has been known that VEGFA and FGF2 are present and active in the ovary there are still a number of questions that remain unanswered. For example, what are the exact roles of FGF2, VEGFA and their different isoforms? Are they both required for angiogenesis? Furthermore, there are numerous other angiogenic controlling factors expressed during early CL development that have a potential roles in either stimulating or inhibiting luteal angiogenesis. However, currently there is no in vitro method that contains all the cell types in the $\mathrm{CL}$ to evaluate the exact roles of these different angiogenic factors and their interactions. Hence, the objective of this study was to develop a physiologically relevant culture system which mimicked luteal angiogenesis, was regulated by angiogenic factors and produced progesterone.

\section{Results}

\section{Development of endothelial structures in a novel luteal angiogenesis culture system}

After 2 days in culture, clusters of endothelial cells started to form, alongside isolated endothelial cells (Fig. 1A). Then by day 5 , these clusters had developed, forming plaques of endothelial cells. Moreover, there was evidence of thread-like structures projecting from around the plaques (Fig. 1B). After 9 days in culture, these tubulelike structures had lengthened, thickened and formed
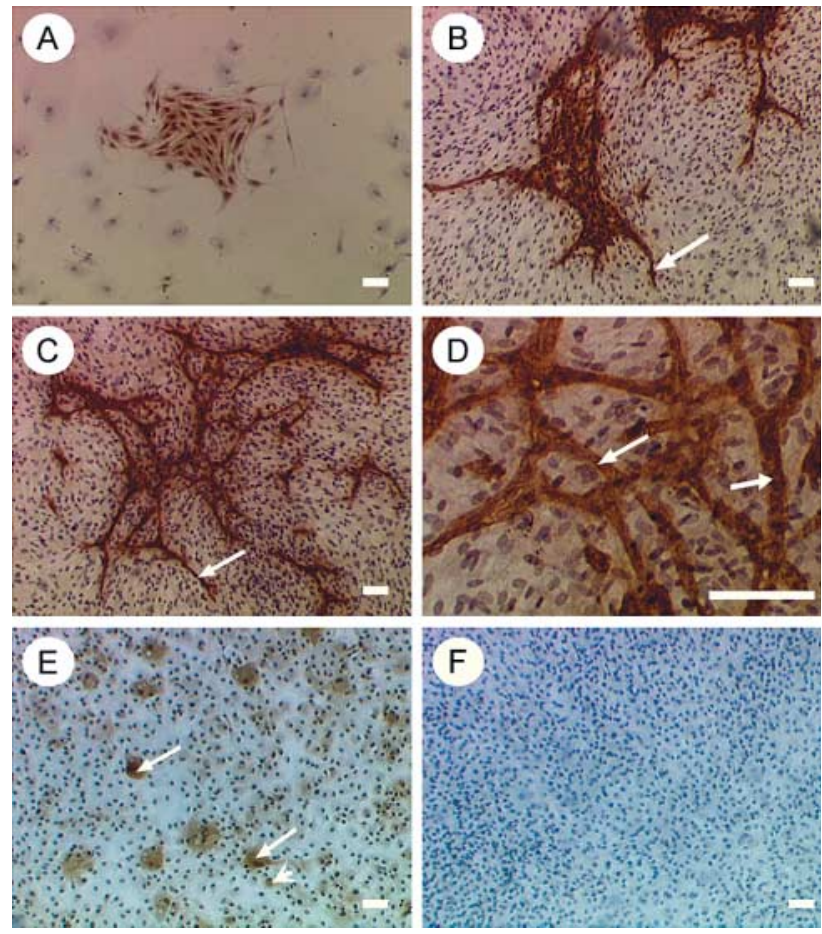

Figure 1 The development of endothelial tubule-like structures in vitro in the luteal angiogenesis culture system. A mixed population of cells dispersed from early $\mathrm{CL}$ was cultured in specialized endothelial cell medium for (A) 2 days, (B) 5 days and (C and D) 9 days prior to being immunostained for VWF. These images show the formation of intricate networks of endothelial tubule-like structures (indicated by arrows) and are shown at higher magnification in (D). Steroidogenic cells immunostained for $3 \beta-\mathrm{HSD}$, with the arrows and arrowheads demonstrating the presence of large and small luteal cells respectively, are shown in (E). Cells treated with rabbit immunoglobulin are shown in (F). The scale bar represents $50 \mu \mathrm{m}$.

highly organized, intricate networks, which superficially resembled a capillary bed (Fig. 1C). Under higher magnification, they had a definite tubule-like appearance with more intense staining on the outer edge (Fig. 1D). Both large and small steroidogenic cells were present in this system as determined by $3 \beta$-HSD ( $3 \beta$-hydroxysteroid dehydrogenase) immunostaining (Fig. 1E). The cells treated with rabbit IgG were blank (Fig. 1F).

\section{Experiment 1: effect of extra-cellular matrix on formation of endothelial networks}

Endothelial tubules developed on plastic alone (Fig. 2A). Collagen (Fig. 2B) had no benefit, while fibronectin (Fig. 2C) enhanced the formation of endothelial tubulelike structure. Image analysis showed that the total area of von Willebrand factor (VWF) staining was increased by 8.4-fold when the coverslips were coated with fibronectin $(P<0.001$, Fig. 2E). Collagen coating, however, had no effect on the total area of endothelial cells $(P>0.15$, Fig. 2E). Hence, fibronectin was used to coat the wells for all subsequent experiments. 

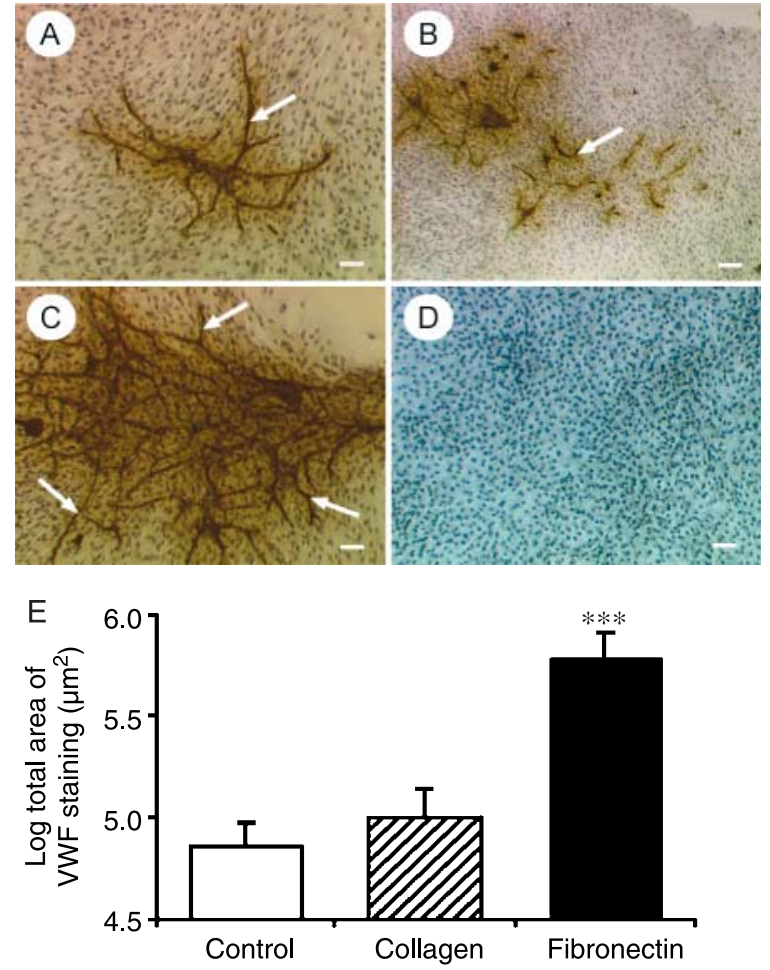

Figure 2 The effects of collagen and fibronectin coating on luteal angiogenesis in vitro. Endothelial cells were immunostained with VWF and representative images are shown for (A) plastic alone (Cont), (B) $20 \mu \mathrm{g} /$ well collagen, (C) $10 \mu \mathrm{g} /$ well fibronectin and (D) rabbit immunoglobulin control ( $n=3$ per treatment). The total area of VWF staining was quantified $(\mathrm{E})$ and shows that fibronectin increased total area of VWF staining $\left(P<0.001 ;{ }^{* * *}\right.$ versus control). The data are mean \pm s.E.M. The scale bar represents $50 \mu \mathrm{m}$.

\section{Experiment 2: effect of $\mathrm{LH}$ on progesterone production and on formation of endothelial networks}

There was a day $\times \mathrm{LH}$ interaction in the production of progesterone $(P<0.001)$. Progesterone production was similar on days 1 and 4 and was unaffected by LH. However, on day 8, basal progesterone production increased threefold and furthermore responded to LH $(P<0.001$, Fig. 3A). LH $(100 \mathrm{ng} / \mathrm{ml})$ increased progesterone production by 2.3 -fold and intermediate production was observed with $5 \mathrm{ng} / \mathrm{ml} \mathrm{LH}$ (Fig. 3A). There was no LHXFGF2 and VEGFA interaction $(P>0.15)$; however, the progesterone synthesis was increased by the addition of FGF2 with VEGFA by $30 \%(P<0.01)$ and the effect was greatest on day 8 of culture (Fig. 3B).

Endothelial tubules were formed in the absence and presence of $\mathrm{LH}$ at all doses (Fig. 4A-D). Quantification of the VWF staining showed that $\mathrm{LH}$ increased the total area in a dose-dependent manner in the absence and presence of FGF2 and VEGFA $(P<0.01$, Fig. 4E). Namely, the total area positively stained for VWF was increased by $100 \mathrm{ng} / \mathrm{ml} \mathrm{LH}$ by nearly twofold $(P<0.01)$ with intermediate levels observed with $5 \mathrm{ng} / \mathrm{ml} \mathrm{LH}$,
A

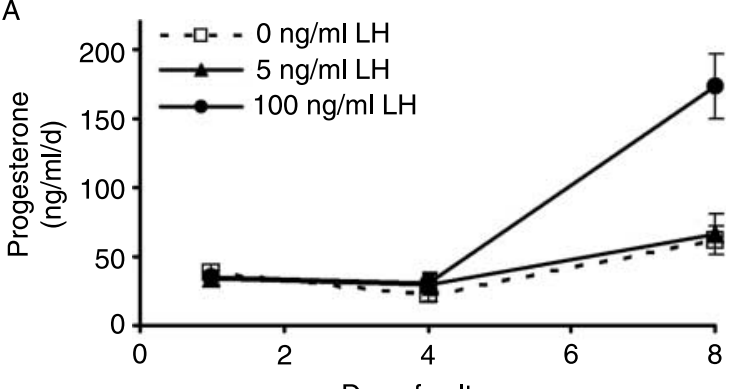

B

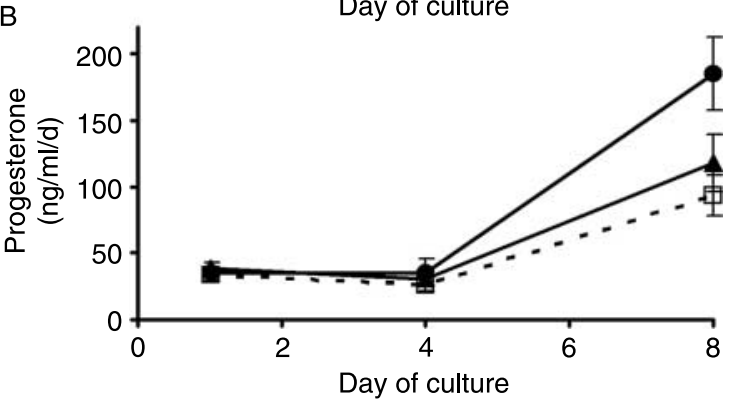

Figure 3 The effect of $\mathrm{LH}$ on the production of progesterone during culture in the in vitro luteal angiogenesis system in the absence (A) and presence (B) of FGF2 and VEGFA. The cells were either treated with 0 $(\cdots \square \cdots), 5(-\mathbf{\Delta}-)$ or $100(-\mathbf{-}-) \mathrm{ng} / \mathrm{ml} \mathrm{LH}(n=5$ per treatment). There was a significant day $(P<0.001), \mathrm{LH}(P<0.001)$ and addition of FGF2 and VEGFA effect $(P<0.05)$. The data are mean \pm s.E.M.

although these were not significant $(P>0.15)$. However, there was no FGF2 and VEGFA $\times$ LH interaction. In comparison, FGF2 and VEGFA increased endothelial total area by 12 -fold $(P<0.001)$. LH increased total area of endothelial cells by increasing the number of angiogenic clusters $(P<0.05)$ but had no effect on the area of each cluster ( $P>0.15$; data not shown).

\section{Experiment 3: Effect of FGF2 and VEGFA on formation of endothelial networks}

As before, in the absence of any exogenous FGF2 and VEGFA, endothelial tubules were formed albeit to a very limited extent (Fig. 5A). The addition of FGF2 or VEGFA alone was able to stimulate the formation of tubules (Fig. 5B and C), but the greatest development of endothelial networks required both factors (Fig. 5D). The image analysis and quantification of these observations is shown in Fig. 6. VEGFA alone increased the number of angiogenic clusters by nearly threefold $(P<0.001)$, while FGF2 had no effect $(P>0.15)$. Both FGF2 $(P<0.001)$ and VEGFA $(P<0.01)$ increased the mean area of each cluster by 71 and $31 \%$ respectively, but there was no interaction. Consequently, the total area of VWF staining was increased by both FGF2 (2.8-fold) and VEGFA alone (4.6-fold) as well as in combination (8.5-fold; $P<0.001$, Fig. 6C). Again, there was no interaction between FGF2 and VEGFA $(P>0.15)$. The perimeter of each cluster and total perimeter area were also determined as this indicated the degree of the formation of these endothelial tubule 


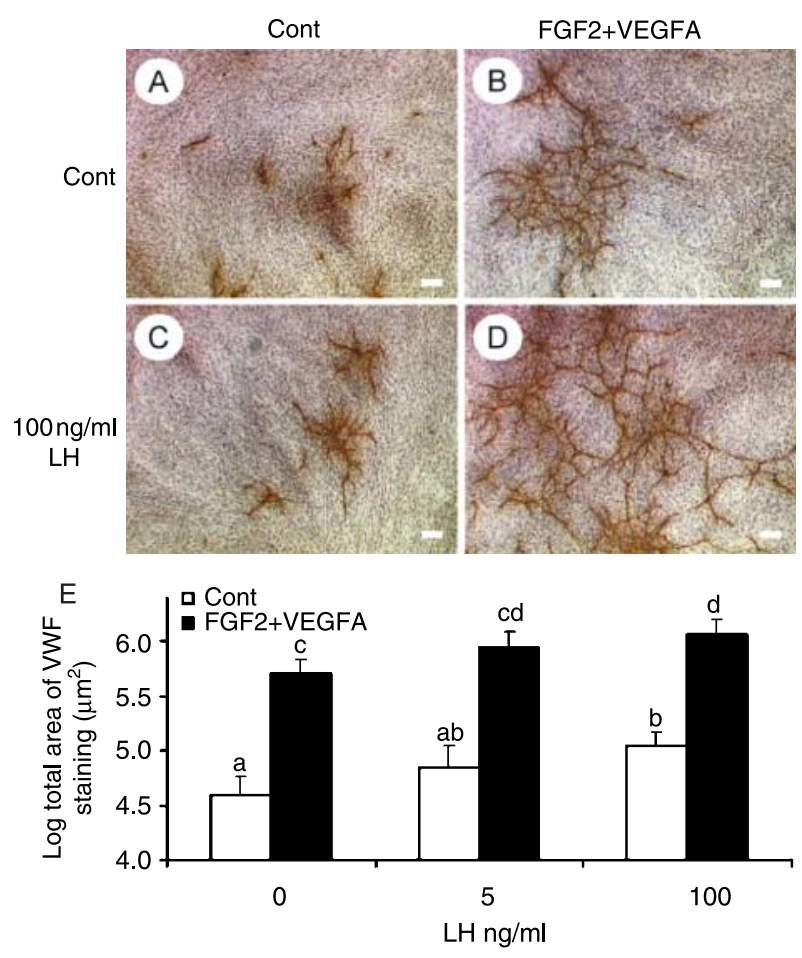

Figure 4 The effect of $\mathrm{LH}$ on the development of luteal vasculature in vitro. Representative images of endothelial tubule development of

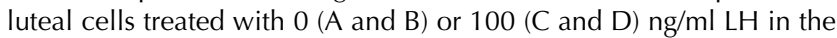
absence ( $A$ and $C$ ) or presence ( $B$ and D) of FGF2 + VEGFA. The endothelial cells were immunostained with VWF (brown). The scale bar represents $50 \mu \mathrm{m}$. The quantification of the total area of VWF staining and the effect of $\mathrm{LH}$ in the absence (open bars) and presence (closed) of FGF2 + VEGFA is shown in (E). LH $(P<0.01)$ increased total endothelial area in the presence and absence of FGF2 + VEGFA $(\mathrm{a}<\mathrm{b}<\mathrm{c}<\mathrm{d}, \mathrm{P}<0.05)$. The data are mean \pm s.E.M.
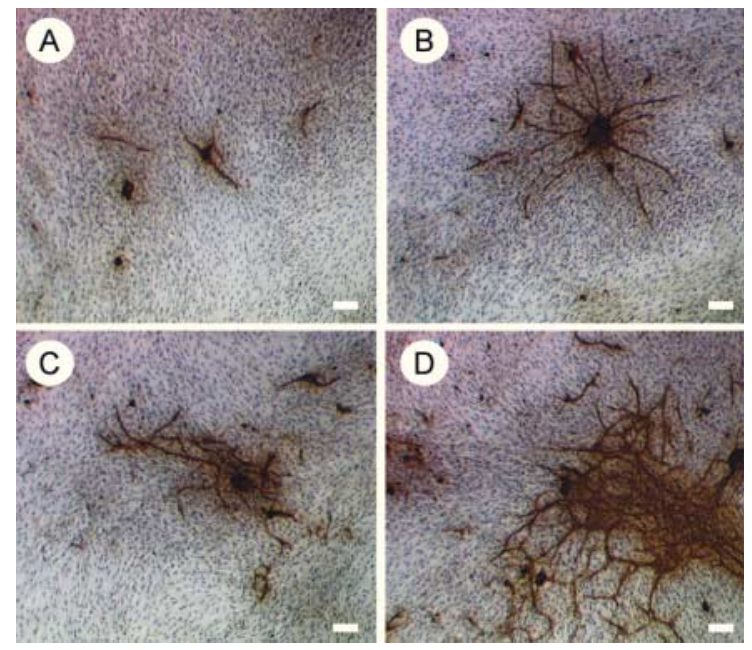

Figure 5 The effect of FGF2 and VEGFA on luteal angiogenesis in vitro. Representative images of the endothelial tubule development of dispersed luteal cells treated with either (A) control, (B) $1 \mathrm{ng} / \mathrm{ml} \mathrm{FGF2,}$ (C) $1 \mathrm{ng} / \mathrm{ml}$ VEGFA or (D) $1 \mathrm{ng} / \mathrm{ml}$ FGF2 with $1 \mathrm{ng} / \mathrm{ml}$ VEGFA are shown. The endothelial cells were immunostained (brown) with VWF. The scale bar represents $50 \mu \mathrm{m}$.
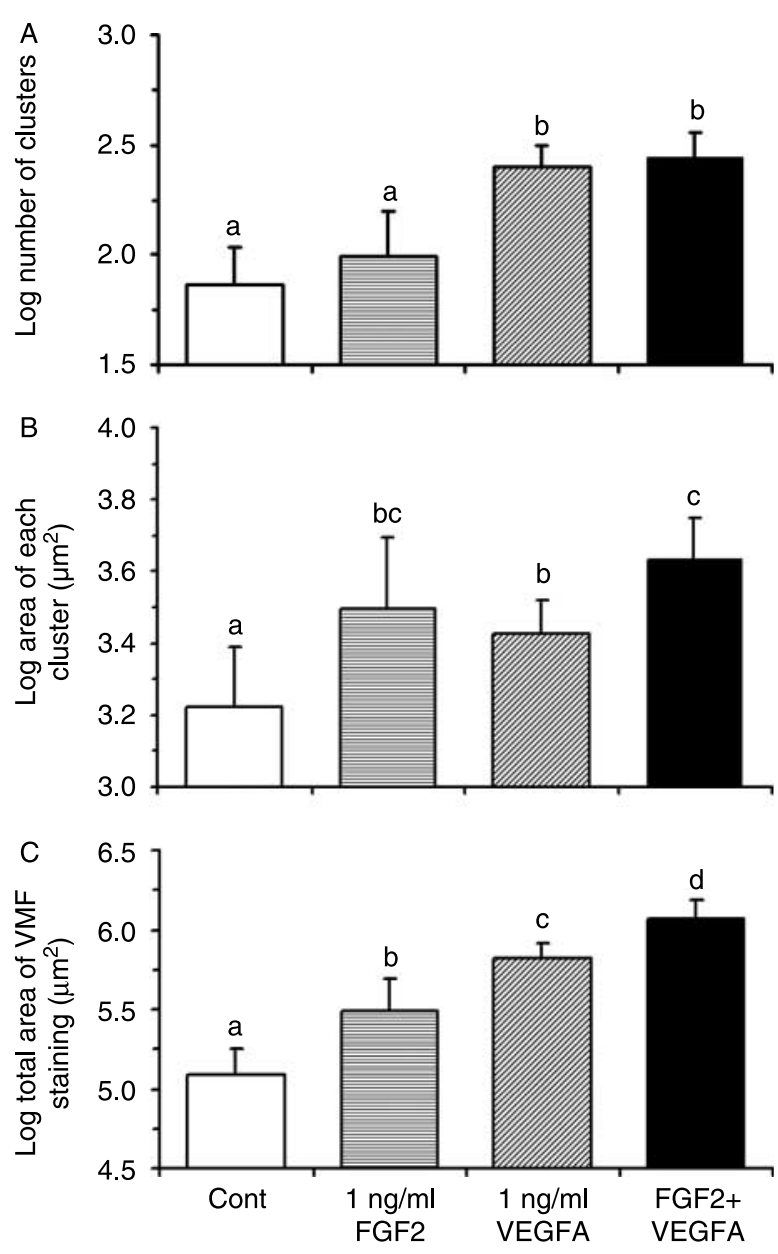

Figure 6 The effects of FGF2 and VEGFA on vasculature development in vitro. The luteal cells were dispersed from early CLs $(n=5)$ and treated with control (open bars), $1 \mathrm{ng} / \mathrm{ml}$ FGF2 (horizontal bars), $1 \mathrm{ng} / \mathrm{ml}$ VEGFA (hatched bars) or $1 \mathrm{ng} / \mathrm{ml}$ FGF2 $+1 \mathrm{ng} / \mathrm{ml}$ VEGFA (closed bars) for 9 days. The image analysis and quantification of the development of the endothelial networks are shown as (A) the number of angiogenic clusters, (B) mean area of each endothelial cluster and (C) total area of VWF staining. In all three parameters, significant differences between the groups are indicated by different $\mathrm{a}<\mathrm{b}<\mathrm{c}<\mathrm{d}$; $P<0.05$ and the values are mean + S.E.M.

networks. FGF2 (by $21 \% ; P<0.05$ ) but not VEGFA $(P>0.15)$ increased the perimeter of each cluster (data not shown). Both factors increased the total perimeter area $(P<0.01$; data not shown).

\section{Discussion}

In the present study, a novel physiological in vitro system, which utilizes primary cells derived from the $\mathrm{CL}$, has been developed that mimics angiogenesis. In this system, tubule-like structures are produced, branch points are formed and after 9 days in culture, a network of endothelial cells has developed, which resembles a capillary bed. Furthermore, the development of vasculature in vitro was stimulated by physiological doses of LH, FGF2 and VEGFA. 
While a number of cell culture systems have been developed to investigate angiogenesis, the vast majority use a combination of cell lines such as human umbilical vein endothelial cells (HUVECs) or bovine aortic endothelial cells (BAEC) with human fibroblasts (Bishop et al. 1999, Kunz-Schughart et al. 2006) rather than primaryderived cells. While these systems provide an invaluable tool to screen potential pro- and anti-angiogenic compounds for use in tissue repair and treatment of diseases such as cancer, they are less relevant to study the physiological mechanisms controlling angiogenesis. Other in vitro angiogenesis systems have used either primary endothelial cells alone (e.g. Bagavandoss \& Wilks 1991, Davis et al. 2003, Hirschberg et al. 2005) or endothelial cell derived from embryonic stem cells (Hermant et al. 2007). In these systems, endothelial cell network and tubule structures are formed but generally only after longterm culture. Furthermore, angiogenesis in vivo involves the communication between numerous different cell types (e.g. pericytes, fibroblasts, large and small luteal cells), hence the physiological relevance of these systems is limited. This probably explains why long-term culture is required for tubule formation in solely endothelial cultures (Hirschberg et al. 2005). For example, pericytes in the developing $\mathrm{CL}$ are closely associated with the leading tip of capillary sprouts (Amselgruber et al. 1999) and steroidogenic cells are a source of VEGFA (Berisha et al. 2000b) and FGF2 (Berisha et al. 2006). Hence, an important feature of our culture system was the co-culturing of primary endothelial with all other luteal cell types derived from the CL. Hence, the endothelial cells will be exposed to a similar environment to the in vivo situation (e.g. similar cell types such as small and large luteal cells and pericytes all at similar ratios). Furthermore, steroidogenic cells were present and, more importantly, are functional as determined by progesterone production, which increased with time in culture and responded to $\mathrm{LH}$. In fact, these in vitro effects showed great temporal similarity to those observed in vivo, namely the rise in plasma progesterone and $\mathrm{LH}$ responsiveness first occur 4-5 days after ovulation (Niswender et al. 2000, Mann \& Lamming 2001, Robinson et al. 2006). The characteristics of the endothelial cells themselves are an important feature since, despite common morphological and functional properties, there is much heterogeneity both between tissues and within a particular tissue (Bagavandoss \& Wilks 1991, Davis et al. 2003). For example, Plendl et al. (1996) showed that endothelial cells derived from a pregnant $C L$ formed connected ring-like structure after prolonged culture, while no such structures were observed from those isolated from the cyclic CL. Hence, we have used primary endothelial-derived cells from very early $\mathrm{CL}$, which were able to form tubule-like structures with branch points, both in a similar manner to other cell line systems (Bishop et al. 1999, Donovan et al. 2001) and reproducibly. A further refinement to this system would be to make it truly three dimensional with the use of collagen gels as recently described (Kunz-Schughardt et al. 2006, Zhao et al. 2007).

The importance of the extra-cellular matrix components on vasculature development was demonstrated by the formation of endothelial networks being greatly increased by fibronectin coating, while collagen I coating had little or no effect. This is in strong agreement with Christenson \& Stouffer (1996) who demonstrated that fibronectin but not collagen I increased luteal endothelial cell proliferation in response to VEGFA. This is also supported by the in situ observations that fibronectin abundance is particularly high during the early growth phase of the $\mathrm{CL}$ while collagen I is relatively low, which again emphasizes its physiological relevance. Then as the $\mathrm{CL}$ develops, the fibronectin:collagen ratio decreases, enabling a firm structure to be formed (Silvester \& Luck 1999, Irving-Rodgers et al. 2006). Moreover, Amselsgruber et al. (1999) reported that initial endothelial sprouts were characterized by a fibrillary network of fibronectin. This is similar to changes in extra-cellular matrix during wound repair (Silvester \& Luck 1999). These suggest that fibronectin rather than collagen I plays a crucial role in the structural backbone for the development of vasculature. Fibronectin has been shown to stimulate endothelial cell adhesion, migration and growth (Milner 2007). Moreover, this suggests that disposition of fibronectin and its cell source are the drivers of luteal angiogenesis.

It is widely accepted that $\mathrm{LH}$ is crucial for luteal development and function; however, less is known about its direct role in angiogenesis. We have previously shown that follicular FGF2 was increased by the LH surge, suggesting that $\mathrm{LH}$ initiates the angiogenesis (Robinson et al. 2007). Moreover, LH is known to stimulate FGF2 (Robinson et al. 2007) and VEGFA (Schams et al. 2001) production in luteal and granulosa cells respectively. The present study confirmed the ability of LH to promote the development of endothelial networks and strengthens its role in angiogenesis. This builds on in vivo observations where GnRH antagonist inhibited the post-ovulatory peak in proliferation by $90 \%$ in primates (Dickson \& Fraser 2000). However, hCG, but not LH, stimulated sprout formation in endothelial-granulosa spheroids (Walz et al. 2005). In the current study, it is unclear whether LH acted on endothelial cells directly or by acting on luteal cells to stimulate the production of angiogenic factors. The latter is more likely since no $\mathrm{LH}$ receptors have been detected on luteal endothelial cells (Mamluk et al. 1998). Furthermore, LH increased FGF2 concentrations 50\% in bovinedispersed luteal cells (Robinson et al. 2007). The effect of $\mathrm{LH}$ in the presence FGF2 and VEGFA antagonists during the culture warrants further investigation.

It is well recognized that FGF2 and VEGFA are critical angiogenic growth factors in the $\mathrm{CL}$; however, their precise roles remain to be elucidated. Both FGF2 and VEGFA alone and in combination stimulated the development of endothelial networks and thus provided further validation of the culture system. Moreover, the 
image analysis of these networks revealed a particularly interesting observation that the pre-dominate effect of FGF2 was to increase the size of the endothelial cluster rather than their numbers. VEGFA, however, had a lesser effect on cluster size but increased the number of clusters. The development of endothelial networks occurred in stages in the present study, similar to previous observations in isolated endothelial cells (Hirschberg et al. 2005). Specifically, the stages are migration and clustering, then sprouting, cellular alignment and tubule initiation followed by network establishment and finally threedimensional organization (Hirshberg et al. 2005). Our results suggest that VEGFA increases endothelial clusters by promoting endothelial cell survival, migration and proliferation of the initial angiogenic clusters, while predominant action of FGF2 was involved in the development of these clusters by inducing sprouting and tubule initiation. This is in agreement with other reports of distinct FGF2 and VEGFA actions in various systems (Parsons-Wingerter et al. 2000, Castellon et al. 2002). For example, Castellon et al. (2002) showed that only platelet-derived growth factor BB and FGF2 were capable alone of inducing secondary sprouting in bovine retinal endothelial cells. While VEGFA increased migration, FGF2 was ineffective. Testing of these hypotheses with targeted use of FGF2 and VEGFA receptor inhibitors certainly warrants further investigation. Furthermore, there were no interactions between the effects of VEGFA and FGF2 that both were required for maximal angiogenic response. This indicates that their effects were additive and that they have independent and different actions on the angiogenic process itself.

In conclusion, the successful development of endothelial cell networks in vitro in a physiologically relevant manner heralds a new era in elucidating the physiological control of the angiogenic process in the developing $\mathrm{CL}$. Future studies will be conducted that mimic the in vivo dynamics of FGF2 and VEGFA expression during the follicle-luteal transition, i.e. a transient high dose of FGF2 and elucidation of the exact roles of FGF2 and VEGFA at the different stages of angiogenesis. Also, we are planning to adapt the culture system to study follicular angiogenesis. Finally, future work will involve determining the role of the other cell types and in particular the potential interactions of endothelial cells and pericytes.

\section{Materials and Methods}

All materials were purchased from Fisher Scientific, Loughborough, UK unless stated.

\section{Establishment of luteal angiogenesis culture system}

Coating of coverslips

Coverslips (circular, $19 \mathrm{~mm}$ diameter $\times 0.25 \mathrm{~mm}$ thick, SLS, Nottingham, UK) were soaked in $70 \%(\mathrm{v} / \mathrm{v})$ industrial methylated spirits (IMS) for $30 \mathrm{~min}$, air-dried for $1 \mathrm{~h}$ and then transferred to a 12 -well plate. Fibronectin ( $1 \mathrm{ml}$ of $10 \mu \mathrm{g} / \mathrm{ml}$; Sigma; optimized in Expt 1a, see below) was added to each well and incubated in humidified incubator at $39^{\circ} \mathrm{C}$. After $4 \mathrm{~h}$, the fibronectin was removed and the wells were left to dry at $39^{\circ} \mathrm{C}$ overnight. On the following day, the wells were washed once with sterile distilled water and allowed to equilibrate with endothelial cell medium (Cambrex, Wokingham, UK) until cell plating.

\section{Endothelial cell medium (EC medium)}

The medium used for the luteal angiogenesis culture was a specialized endothelial cell medium (EBM-2; Cambrex) to which gentamycin, heparin, human epidermal growth factor (EGF), LR ${ }^{3}$-insulin-like growth factor-I (IGF-I), hydrocortisone and ascorbic acid were added as per the manufacturer's instructions. In addition, the medium was supplemented with $5 \mathrm{ng} / \mathrm{ml}$ LH (AFP11743B, biopotency $1.06 \times$ oLH NIDDK-I-2; a gift from Dr A F Parlow, NIDDK, Torrance, CA, USA), 100 units $/ \mathrm{ml}$ penicillin, $10 \mu \mathrm{g} / \mathrm{ml}$ streptomycin, $10 \mu \mathrm{g} / \mathrm{ml}$ insulin, $5.5 \mu \mathrm{g} / \mathrm{ml}$ transferrin, $5 \mathrm{ng} / \mathrm{ml}$ selenium (all Sigma) and $2 \%(\mathrm{v} / \mathrm{v}$ ) foetal bovine serum (Cambrex).

\section{Tissue collection and luteal angiogenesis culture system}

Ovaries were collected from a local abattoir and transported back to the laboratory in $1 \times$ PBS at room temperature. In all experiments, only early $\mathrm{CL}$ (days $1-4$ ) were used and these were selected based on criteria outlined by Ireland et al. (1980). The CLs were removed from the ovary with all connective tissue trimmed away and then sliced up using scissors. All cells (including luteal, endothelial, pericytes and fibroblasts) were dispersed by incubating the luteal tissue in DMEM/F12 medium (Invitrogen) containing $2 \mathrm{mg} / \mathrm{ml}$ collagenase I type 1A and $25 \mu \mathrm{g} /$ $\mathrm{ml}$ DNase I (both Sigma) for $2 \times 45 \mathrm{~min}$ in a shaking water bath at $37^{\circ} \mathrm{C}$. The dispersed cells from each incubation were pooled together and then filtered through $70 \mu \mathrm{m}$ cell strainer (BD Biosciences, Oxford, UK) and washed thrice in endothelial cell medium. The cells were then plated out at $2 \times 10^{5}$ viable cells (as determined by trypan blue exclusion; Tennant 1964) per well in a 12-well plate (total volume: $2 \mathrm{ml}$ ) at $39^{\circ} \mathrm{C}$ in a humidified incubator in $5 \% \mathrm{CO}_{2} / 95 \%$ air. The cells were allowed to attach for $24 \mathrm{~h}$ and thereafter every 2 days the medium was changed. After 2,5 and 9 days, the medium was collected and the cells fixed in acetone:methanol $(1: 1)$ at room temperature for $5 \mathrm{~min}$. The endothelial cells were then immunostained using VWF as an established endothelial cell marker in order to assess the formation of tubule-like structures over time (Al-zi'abi et al. 2003, Martelli et al. 2006).

\section{Immunostaining of endothelial cell with VWF}

After fixation and each step, the cells were washed twice with $1 \times$ PBS for $5 \mathrm{~min}$ each wash. The first step was to block endogenous peroxidase activity with $3 \%(\mathrm{v} / \mathrm{v})$ hydrogen peroxide in methanol. Non-specific binding was blocked by incubating sections with $20 \%$ normal goat serum (Sigma) for 30 min and with no washing step, the cells were incubated with $4 \mu \mathrm{g} / \mathrm{ml}$ polyclonal rabbit anti-human VWF (Dako, High Wycombe, $\mathrm{UK})$ in $2 \%(\mathrm{v} / \mathrm{v})$ normal goat serum. For the control sections, 
$4 \mu \mathrm{g} / \mathrm{ml}$ rabbit IgG was used. The slides were incubated in a humidified chamber at $4{ }^{\circ} \mathrm{C}$ overnight. On the following day, the primary antibody was detected using the Vectorstain $\mathrm{ABC}$ method as per instructions (Vector, Peterborough, UK) and visualization was performed with diaminobenzidine (Vector). The cells were counterstained with haematoxylin and dehydrated in graded IMS. The coverslips were then removed from the well and further dehydrated in xylene before mounting in DPX mountant.

Immunostaining of steroidogenic cells with $3 \beta-H S D$

The presence of steroidogenic cells was determined by immunostaining for $3 \beta$-HSD. The procedure performed was the same as for VWF except that the primary antibody used was polyclonal rabbit anti-human placental $3 \beta-H S D$ (kindly provided by Dr Richard Parker, University of AlabamaBirmingham, AL, USA; diluted 1 in 400 in PBS).

\section{Quantification of VWF immunostaining by image analysis}

The quantification method was developed, based on a protocol previously used to quantify area of VWF staining in bovine $\mathrm{CL}$ sections (Robinson et al. 2006). All the image analysis was performed using Image Pro-Plus 5.0 (Media Cybernetics, Wokingham, UK). The sections were visualized under a $6 \times$ objective lens and the area of brown (VWF) staining was highlighted. The highlighted area was then smoothed, any holes in the staining removed and any area of VWF staining $<150 \mu \mathrm{m}^{2}$ excluded (in order to eliminate very small cluster of isolated endothelial cells of $<3$ cells). Only areas stained positively for VWF with tubule-like appearance were included in the analysis. The number, area and perimeter of each cluster were recorded. This was repeated for a total of 10 fields of view across the whole well. The total area and perimeter of VWF staining were then calculated by multiplying the number of clusters by the mean area or perimeter. Both wells were examined for each treatment and from this the mean values recorded for each treatment.

\section{Experiment 1: effect of extra-cellular matrix on formation of endothelial networks}

In order to optimize the in vitro luteal angiogenesis culture system, the effect of the extra-cellular matrix coating of the coverslips was investigated. The coverslips were prepared as above and coated as follows: (1) plastic alone, (2) $20 \mu \mathrm{g}$ per well calf skin collagen I (Sigma) or (3) $10 \mu \mathrm{g}$ per well bovine fibronectin (Sigma; $n=3$, early CL for treatment). The cells were dispersed and prepared as described above and were plated out at $2 \times 10^{5}$ cells per well, with 2 wells per each coating. The cells were cultured in endothelial cell medium supplemented with $1 \mathrm{ng} / \mathrm{ml}$ FGF2 and $1 \mathrm{ng} / \mathrm{ml} \mathrm{VEGFA}{ }_{165}$ (Cambrex) throughout the culture. After 9 days in culture, the cells were fixed for $5 \mathrm{~min}$ in acetone:methanol $(1: 1)$ at room temperature, then immunostained for VWF.

\section{Experiment 2: effect of $\mathrm{LH}$ on progesterone production and formation of endothelial networks}

Cultures were prepared from early CL (days $1-4 ; n=5$ ) as described above and the dispersed cells were plated out at $2 \times 10^{5}$ per well and cultured in endothelial cell medium. A $3 \times 2$ factorial design was set-up with effects of $\mathrm{LH}$ (at 0, 5 and $100 \mathrm{ng} / \mathrm{ml}$ ) determined in the presence and absence of $1 \mathrm{ng} / \mathrm{ml}$ $\mathrm{FGF} 2+1 \mathrm{ng} / \mathrm{ml} \mathrm{VEGFA}_{165}$. Each treatment was performed in duplicate. The medium was collected for progesterone analysis and changed after 1, 4, 6 and 8 days. After 9 days, the cells were fixed in acetone:methanol 1:1 at room temperature (RT) for $5 \mathrm{~min}$, then immunostained for VWF.

\section{Progesterone analysis}

The medium was collected and stored at $-20{ }^{\circ} \mathrm{C}$ for progesterone analysis. The progesterone concentration in spent medium was determined in a single assay using RIA as previously validated by Corrie et al. (1981). The samples were diluted 300-fold into RIA buffer and the intra-assay coefficient of variation was $13.7 \%$.

\section{Experiment 3: effect of FGF2 and VEGFA development of endothelial networks}

Luteal cells were dispersed from early CL (days $1-4, n=4)$ and then plated out at $2 \times 10^{5}$ cells per well and were cultured in endothelial cell medium. The cells were then treated with the following: (a) control, (b) $1 \mathrm{ng} / \mathrm{ml} \mathrm{FGF2,} \mathrm{(c)} 1 \mathrm{ng} / \mathrm{ml} \mathrm{VEGFA}_{165}$ or (d) $1 \mathrm{ng} / \mathrm{ml} \mathrm{FGF2}$ and $1 \mathrm{ng} / \mathrm{ml}$ VEGFA $_{165}$ with each treatment performed in duplicate. The medium was changed after 1, 3, 5 and 7 days. After 9 days in culture, the cells were fixed in acetone:methanol $(1: 1)$ at RT for $5 \mathrm{~min}$, then immunostained for VWF. The number, area and perimeter of each cluster as well as the total area and perimeter of the VWF staining were analysed.

\section{Statistical analyses}

All the data were checked for normality and heterogeneity of variance and were log transformed where appropriate.

\section{Experiment 1}

The effect of coating was analysed by one-way randomized block ANOVA with no coating, collagen and fibronectin as factors and blocked for each culture. Bonferroni's multiple comparisons were performed to determine where any significant difference lay.

\section{Experiment 2}

The effect of $\mathrm{LH}$ and FGF+ VEGFA on the production of progesterone was determined using repeated measurements ANOVA with progesterone production per day as the variable and $\mathrm{LH}$ and FGF2 + VEGFA as the factors. A randomized block two-way ANOVA was performed to analyse these factors on endothelial development parameters. Bonferroni's multiple comparisons were performed to determine where any significant difference lay.

\section{Experiment 3}

The effects of FGF2 and VEGFA on endothelial tubule parameters were determined using two-way randomized block ANOVA with presence of FGF2 and VEGFA as factors 
and culture as the block. If there was a significant effect, then one-way randomized block ANOVA were performed to elucidate where the differences lay. For all experiments, $P<0.05$ was considered as significant and all data are quoted as mean \pm s.E.M. unless stated otherwise.

\section{Acknowledgements}

The authors wish to thank Jim Craigon for his statistical guidance. We are also grateful to the staff of Nottingham University for their assistance with sample collection and analysis. The work was supported by the BBSRC grant 42/S/16622. The authors declare that there is no conflict of interest that would prejudice the impartiality of this scientific work.

\section{References}

Al-zi'abi MO, Watson ED \& Fraser HM 2003 Angiogenesis and vascular endothelial growth factor expression in the equine corpus luteum. Reproduction 125 259-270.

Amselgruber WM, Schafer M \& Sinowatz F 1999 Angiogenesis in the bovine corpus luteum: an immunocytochemical and ultrastructural study. Anatomia, Histologia, Embryologia C28 157-166.

Bagavandoss P \& Wilks JW 1991 Isolation and characterization of microvascular endothelial cells from developing corpus luteum. Biology of Reproduction 44 1132-1139.

Berisha B, Schams D, Kosmann M, Amselgruber W \& Einspanier R 2000a Expression and localisation of vascular endothelial growth factor and basic fibroblast growth factor during the final growth of bovine ovarian follicles. Journal of Endocrinology 167 371-382.

Berisha B, Schams D, Kosmann M, Amselgruber W \& Einspanier R 2000b Expression and tissue concentration of vascular endothelial growth factor, its receptors, and localization in the bovine corpus luteum during estrous cycle and pregnancy. Biology of Reproduction 63 1106-1114.

Berisha B, Steffl M, Amselgruber W \& Schams D 2006 Changes in fibroblast growth factor 2 and its receptors in bovine follicles before and after GnRH application and after ovulation. Reproduction 131 319-329.

Bishop ET, Bell GT, Bloor S, Broom IJ, Hendry NFK \& Wheatley DN 1999 An in vitro model of angiogenesis: basic features. Angiogenesis 3 335-344.

Carmeliet P 2003 Angiogenesis in health and disease. Nature Medicine 9 653-660.

Castellon R, Hamdi HK, Sacerio I, Aoki AM, Kenney MC \& Ljubimov AV 2002 Effects of angiogenic growth factor combinations on retinal endothelial cells. Experimental Eye Research 74 523-535.

Christenson LK \& Stouffer RL 1996 Isolation and culture of microvascular endothelial cells from the primate corpus luteum. Biology of Reproduction 55 1397-1404.

Corrie JET, Hunter WM \& Macpherson JS 1981 A strategy for radioimmunoassay of plasma progesterone with use of a homologous site ${ }^{125}$-labeled radioligand. Clinical Chemistry 27 594-599.

Davis JS, Rueda BR \& Spanel-Borowski K 2003 Microvascular endothelial cells of the corpus luteum. Reproductive Biology and Endocrinology $\mathbf{1}$ 89-104.

Dickson SE \& Fraser HM 2000 Inhibition of early luteal angiogenesis by gonadotropin-releasing hormone antagonist treatment in the primate. Journal of Clinical Endocrinology and Metabolism 85 2339-2344.

Donovan D, Brown NJ, Bishop ET \& Lewis CE 2001 Comparison of three in vitro human 'angiogenesis' assays with capillaries formed in vivo. Angiogenesis 4 113-121.

Ferrara N, Gerber HP \& LeCouter J 2003 The biology of VEGF and its receptors. Nature Medicine $\mathbf{9} 669-676$.

Fraser HM \& Lunn SF 2001 Regulation and manipulation of angiogenesis in the primate corpus luteum. Reproduction 121 355-362.

Fraser HM \& Wulff C 2001 Angiogenesis in the primate ovary. Reproduction, Fertility, and Development 13 557-566.
Fraser HM, Dickson SE, Lunn SF, Wulff C, Morris KD, Carroll VA \& Bicknell R 2000 Suppression of luteal angiogenesis in the primate after neutralization of vascular endothelial growth factor. Endocrinology 141 995-1000.

Greenaway J, Gentry PA, Feige J, LaMarre J \& Petrik JJ 2005 Thrombospondin and vascular endothelial growth factor are cyclically expressed in an inverse pattern during bovine ovarian follicle development. Biology of Reproduction 72 1071-1078.

Hermant B, Desroches-Castan A, Dubessay ML, Prandini MH, Huber P \& Vittet D 2007 Development of a one-step embryonic stem cell-based assay for the screening of sprouting angiogenesis. BMC Biotechnology 720.

Hirschberg RM, Sachtleben M \& Plendl J 2005 Electron microscopy of cultured angiogenic endothelial cells. Microscopy Research and Technique 67 248-259.

Ireland JJ, Murphee RL \& Coulson PB 1980 Accuracy of predicting stages of bovine estrous cycle by gross appearance of the corpus luteum. Journal of Dairy Science 63 155-160.

Irving-Rodgers HF, Roger J, Luck MR \& Rodgers RJ 2006 Extracellular matrix of the corpus luteum. Seminars in Reproductive Medicine $\mathbf{2 4}$ 242-250.

Kamada D, Matsui M, Shibanuma T, Yamamoto D, Schams D \& Miyamoto A 2004 Suppression of corpus luteum development at early stage of formation by antibody against vascular endothelial growth factor in the cow. Biology of Reproduction 71196.

Kunz-Schughart LA, Schroeder JA, Wondrak M, Van Rey F, Lehle K, Hofstaedter F \& Wheatley DN 2006 Potential of fibroblasts to regulate the formation of three-dimensional vessel-like structures from endothelial cells in vitro. American Journal of Physiology. Cell Physiology 290 C1385-C1398.

Larson SF, Butler WR \& Currie WB 1997 Reduced fertility associated with low progesterone postbreeding and increased milk urea nitrogen in lactating cows. Journal of Dairy Science 80 1288-1295.

Mamluk R, Chen DB, Greber Y, Davis JS \& Meidan R 1998 Characterization of messenger ribonucleic acid expression for prostaglandin F-2 alpha and luteinizing hormone receptors in various bovine luteal cell types. Biology of Reproduction 58 849-856.

Mann GE \& Lamming GE 2001 Relationship between maternal endocrine environment, early embryo development and inhibition of the luteolytic mechanism in cows. Reproduction 121 175-180.

Martelli A, Berardinelli P, Russo V, Mauro A, Bernabo N, Gioia L, Mattioli M \& Barboni B 2006 Spatio-temporal analysis of vascular endothelial growth factor expression and blood vessel remodelling in pig ovarian follicles during the periovulatory period. Journal of Molecular Endocrinology 36 107-119.

Milner R 2007 A novel three-dimensional system to study interactions between endothelial cells and neural cells of the developing central nervous system. BMC Neuroscience 83.

Niswender GD, Juengel JL, Silva PJ, Rollyson MK \& McIntush EW 2000 Mechanisms controlling the function and life span of the corpus luteum. Physiological Reviews 80 1-29.

Parsons-Wingerter P, Elliott KE, Clark JI \& Farr AG 2000 Fibroblast growth factor-2 selectively stimulates angiogenesis of small vessels in arterial tree. Atherosclerosis, Thrombosis, and Vascular Biology 20 1250-1256.

Plendl J, Neumuller C \& Sinowatz F 1996 Differences of microvascular endothelium in the bovine corpus luteum of pregnancy and the corpus luteum of the estrous cycle. Biology of the Cell 87 179-188.

Redmer DA \& Reynolds LP 1996 Angiogenesis in the ovary. Reviews of Reproduction 1 182-192.

Reynolds LP \& Redmer DA 1999 Growth and development of the corpus luteum. Journal of Reproduction and Fertility 54 (Suppl) 181-191.

Reynolds LP, Grazul-Bilska AT \& Redmer DA 2000 Angiogenesis in the corpus luteum. Endocrine 12 1-9.

Robinson RS, Hammond AJ, Nicklin LT, Schams D, Mann GE \& Hunter MG 2006 Endocrine and cellular characteristics of corpora lutea from cows with a delayed post-ovulatory progesterone rise. Domestic Animal Endocrinology 31 154-172.

Robinson RS, Nicklin LT, Hammond AJ, Schams D, Hunter MG \& Mann GE 2007 FGF2 is more dynamic than VEGFA in during the follicle-luteal transition in the cow. Biology of Reproduction 77 28-36.

Schams D \& Berisha B 2004 Regulation of corpus luteum function in cattle-an overview. Reproduction in Domestic Animals 39 241-251. 
Schams D, Kosmann M, Berisha B, Amselgruber WM \& Miyamoto A 2001 Stimulatory and synergistic effects of luteinising hormone and insulin like growth factor 1 on the secretion of vascular endothelial growth factor and progesterone of cultured bovine granulosa cells. Experimental and Clinical Endocrinology and Diabetes 109 155-162.

Silvester LM \& Luck MR 1999 Distribution of extracellular matrix components in the developing ruminant corpus luteum: a wound repair hypothesis for luteinization. Journal of Reproduction and Fertility 116 187-198.

Tennant JR 1964 Evaluation of the trypan blue technique for determination of cell viability. Transplantation 2 685-694.

Walz A, Keck C, Weber H, Kissel C \& Pietrowski D 2005 Effects of luteinizing hormone and human chorionic gonadotropin on corpus luteum cells in a spheroid cell culture system. Molecular Reproduction and Development 72 98-104.
Wiedlocha A \& Sorensen V 2004 Signaling, internalization, and intracellular activity of fibroblast growth factor. Current Topics in Microbiology and Immunology 286 45-79.

Zhao Y, Tan YZ, Zhou LF, Wang HJ \& Mao Y 2007 Morphological observation and in vitro angiogenesis assay of endothelial cells isolated from human cerebral cavernous malformations. Stroke 38 1313-1319.

Zimmermann RC, Hartman T, Bohlen P, Sauer MV \& Kitajewski J 2001 Preovulatory treatment of mice with anti-VEGF receptor 2 antibody inhibits angiogenesis in corpora lutea. Microvascular Research 62 15-25.

Received 10 August 2007

First decision 7 September 2007

Accepted 30 October 2007 